

\section{To Be Specifico....}

\section{The specifications for the New York City Department of Sanitation refuse haulers are listed below:}

Chassis:

Crane Carrier Corporation Model LT484M, 25-cubic-yard capacity, low-entry cab

Fuel: compressed natural gas

Gross Vehicle Weight: 70,000 pounds

Engine:

Displacement: 1992 Cummins L10-240G

10 liters

Power:

240 horsepower

Torque:

Gas Cylinders:

Capacity:

\section{0 foot-pounds}

Pressed Steel Tank Company

36 diesel equivalent gallons

According to Harte, "These vehicles are so quiet, our workers can listen to the radio on routes. With the diesel engines, that's impossible."

The U.S. Department of Energy (DOE) sponsors this project. The Alternative Fuels Data Center (AFDC) at DOE's National Renewable Energy Laboratory (NREL) has been accumulating refueling and maintenance data on these trucks since October 1992. As of September 1995, more than 2000 refueling records and hundreds of repair records have been collected and studied.

\section{Fuel Economy and Range}

$\mathrm{B}$ ecause the CNG engines are sparkignited, throttled engines, they should show a slightly lower fuel efficiency than a diesel engine because of pumping losses. Pumping losses are the amount of energy required for the engine to draw in air through the throttle during the intake cycle. Because a diesel engine has no throttle, the pumping losses are much smaller.

The average fuel economy of the CNG refuse haulers and that of an equivalent diesel refuse hauler are shown in

Figure 1. The fuel economies are presented in miles per diesel equivalent gallon, which allows for a direct comparison between the CNG and diesel trucks. A diesel equivalent gallon is the amount of CNG that has the same energy content as a gallon of diesel fuel. The fuel efficiency of the CNG trucks has been between $5 \%$ and $20 \%$ lower than that of the diesel truck. This is within the 
Five gas cylinders give the refuse baulers a range of about 61 miles.

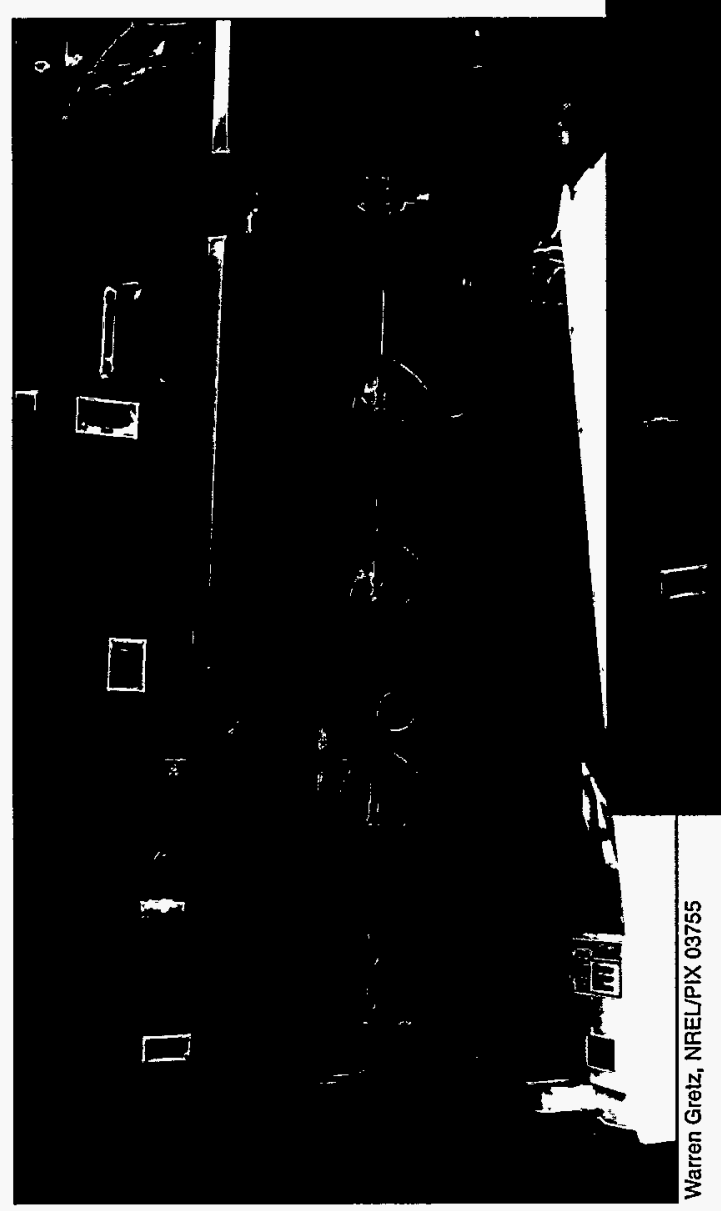

expected range for the difference in efficiency between a spark-ignited, throttled engine and a diesel engine.

The diesel trucks carry 50 gallons of diesel fuel, which gives the trucks a range of about 95 miles between refuelings. The gas cylinders in the CNG trucks can carry the energy equivalent of about 36 diesel gallons in natural gas. Therefore the average range of the New York City CNG trucks is about 61 miles, which has been acceptable for the New York City refuse haulers because their routes are within the city and tend to be short. The Department of Sanitation has been refueling the trucks only once every other day on the average.

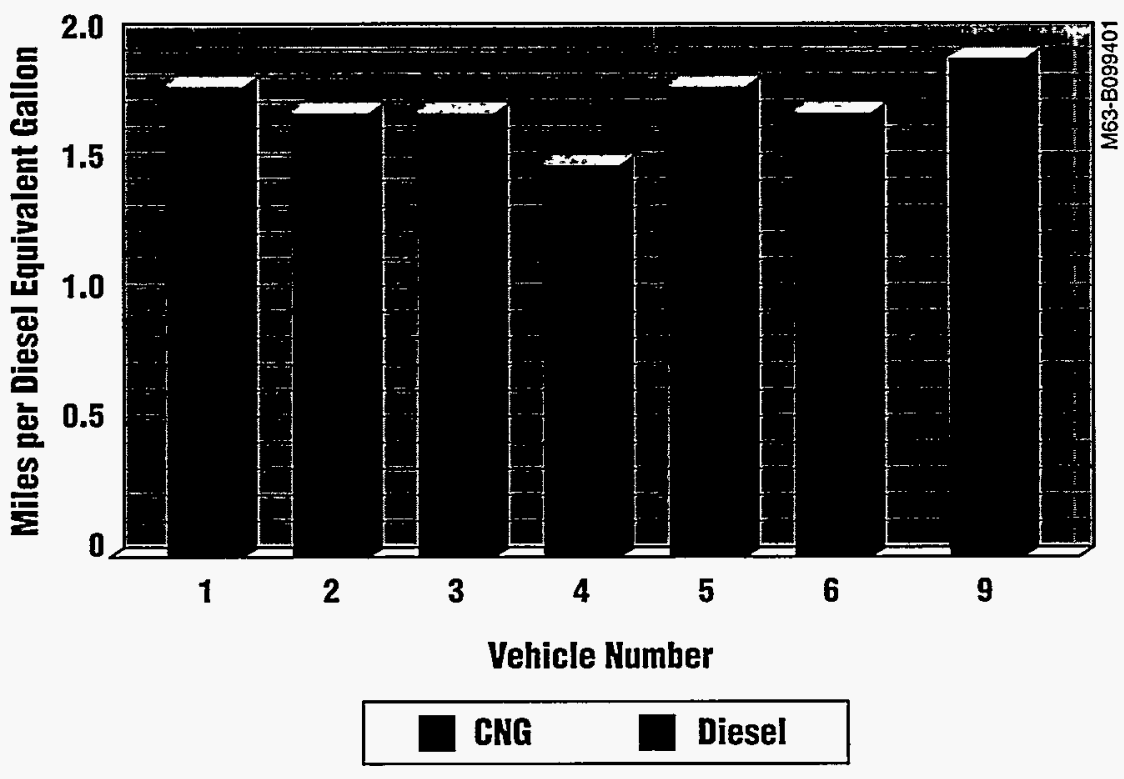

Figure 1. Average in-use fiel economy of the NYC refuse baulers from October 1992 to September 1995

"We refuel the collection trucks every other day just like the diesels,"
Manager Tim Harte explained to New York's Clean Rider magazine.
"Refueling is quick and easy and takes only a few minutes." 


\section{Cost}

$\mathrm{O}$ $\mathrm{n}$ an equivalent energy basis, the retail price of natural gas is lower than that of diesel fuel. In the week of January 8, 1996, the national average station price for diesel fuel was about $\$ 1.15$ per gallon. The average station price for CNG was about $\$ 0.96$ per diesel equivalent gallon. On an equal energy basis, CNG cost about $17 \%$ less than diesel. Some of this advantage is lost because the natural gas trucks have lower fuel efficiency than the diesel trucks. Using the average fuel efficiency of the natural gas and diesel refuse haulers in New York City, and the national average retail fuel prices in January 1996, the fuel cost would be about $\$ 0.57$ per mile for the natural gas trucks and $\$ 0.62$ per mile for the diesel trucks. Actual fuel cost at any given site will depend on the local diesel and CNG prices, which can vary significantly from the national average.

The fuel cost savings must be balanced against the additional cost of a CNG truck. The New York City CNG refuse haulers were the first of their kind, and the costs of these prototypes were considerably higher than those of a comparable diesel truck. Experience with these trucks and subsequent demonstration vehicles has convinced major truck manufacturers that there is a place for alternative fuel heavy-duty trucks. In 1996 several manufacturers, including Peterbilt, Kenworth, Mack, Volvo/GM, and Crane Carrier will offer natural gas versions of some of their popular refuse

\section{Where Can I Get One of Thosel}

Because of the experience gleaned from this project and others like it, there are now several truck manufacturers offering natural gas refuse haulers. Here are some of the refuse haulers that are available now with natural gas options, or that will be in the near future:

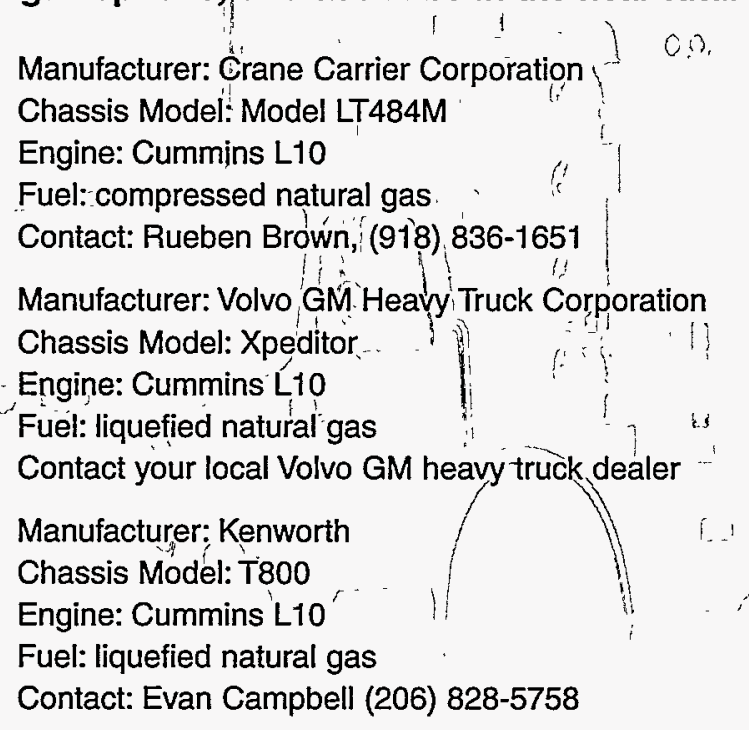

Manufacturer: Peterbilt

Chassis Model: 320

Engine: Cummins L10

Fuel: compressed or liquefied natural gas

Contact your local Peterbilt dealer, 1-800-447-4700

Manufacturer: Mack

Chassis Model: MR Cab-over refuse hauler

Engine: Mack E7

Fuel: liquefied natural gas

Contact: Kevin Flaherty (610) 709-3816 
haulers (see the sidebar entitled "Where

Can I Get One of Those!").

When these new trucks are first released, production volumes are expected to be low, so the cost of the natural gas option may be substantial. As production volumes increase, however, manufacturers expect the cost of the natural gas trucks to drop. Natural gas engines are not inherently more expensive to make than advanced diesel engines, but the natural gas fuel systems will always be more complex and expensive than a diesel fuel system. However, because the fuel system is a small percentage of the total cost of the truck, the cost of a natural gas option will not greatly boost the overall cost of the truck at high production volumes.

\section{Maintenance and Repair Issues}

$\mathrm{B}$ ecause these trucks were the first of their kind, we expected a steady stream of unforeseen problems. But, although problems did occur, the trucks have consistently performed above expectations. The Department of Sanitation has been delighted with them.

The prototypes had a few problems when they first went into service. Early in the project a piston melted down in one of the engines. The problem was traced to the air/fuel ratio control and corrected for the rest of the trucks in the project. The knowledge gained from this type of experience has helped the engine manufacturers greatly improve their fuel control systems on newer natural gas engines.

The maintenance and repair database accumulated on the CNG trucks shows that they have been somewhat more
New York City put 10 new CNG refuse haulers (for a total of 16) into service in 1995.

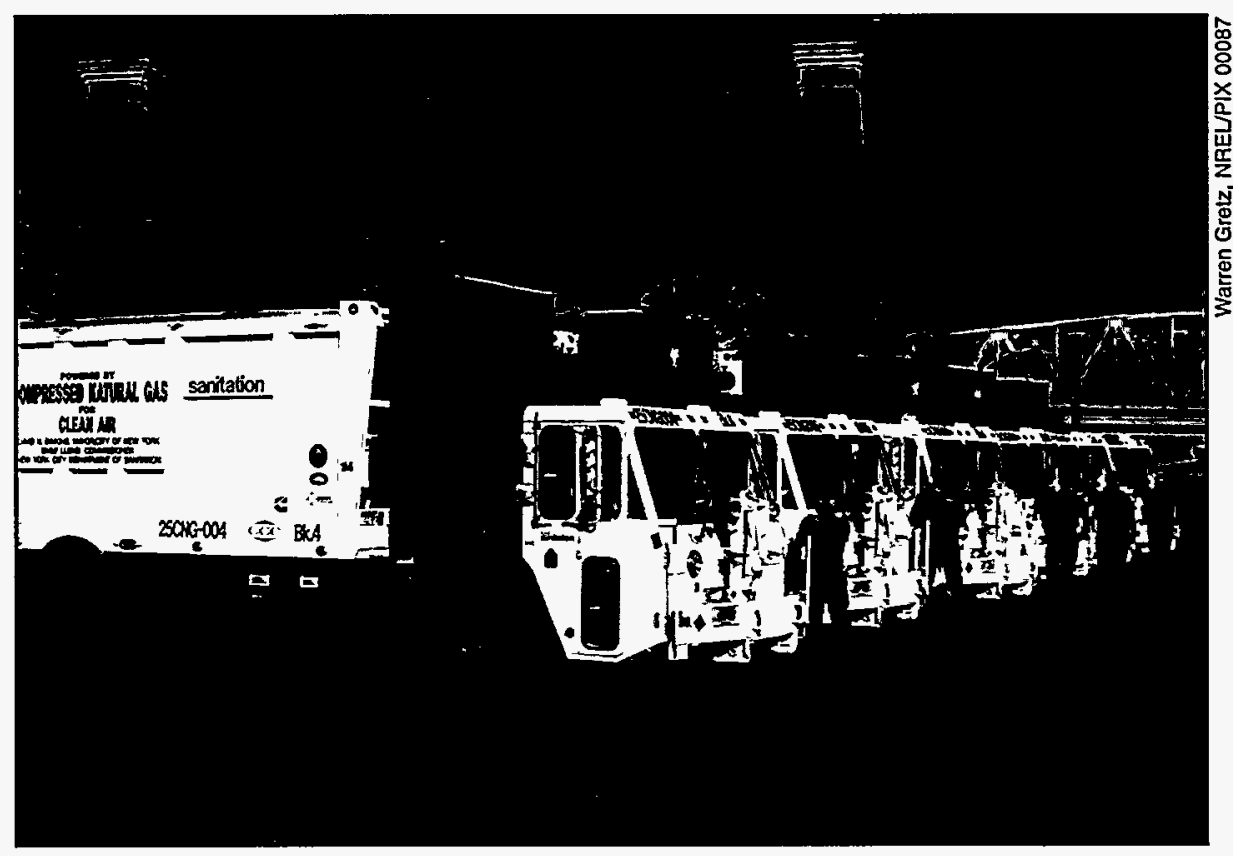

expensive to maintain than the diesel trucks. A significant part of this differential cost has been the spark plugs and wires for the CNG trucks. Tim Harte explains, "In terms of regular maintenance... [the CNG trucks] have been right alongside the rest. The spark plugs and wires were the parts that really caught us by surprise." At the beginning of the project, the spark plug wires had to be replaced every 6 to 8 months at a cost of about $\$ 125.00$ per wire. With the help of the manufacturer, the wire life is now doubled. In their newer natural gas engines, manufacturers have integrated the design of the spark plug wires and coils. This design change should further increase the wire life and reduce maintenance costs. As Tim Harte put it, “..if you didn't start somewhere, you wouldn't find that the weak link is your ignition wire and that's part of why we did this." 


\section{Alternative Fuel Trucks \\ Case Studies}

\section{Lessons Learned}

When asked to outline some of the lessons learned during the Department of Sanitation's experience with the CNG trucks, Harte explained some of the problems the department encountered and their solutions. Through the New York City project and similar demonstration projects sponsored by DOE, such issues are being uncovered and addressed. This makes each generation of alternative fuel trucks more trouble-free and reliable than the last.

\section{Fuel supply}

"Don't put all your eggs in one basket. We have had some areas where the compressor has gone down, and, through no fault of their own, just an availability of products, they haven't been able get the compressor back up for a day or so. So some redundancy or some backup means of getting fuel close by is important."

\section{Fuel contamination}

'We found contaminants in the fuel supply that we didn't expect to find. We installed filters on all the vehicles. They now have coalescent filters in between the fuel filter and the cylinders because of compressor oil and some debris that we found in the fuel, bits and pieces of Teflon tape, thread shavings, things like that. Nothing tremendous, but the compressor oil did cause some problems with the vehicles, regulators, etc."

\section{On-board fuel reserve}

"We put a thousand-pound check valve on the last cylinder. So as the others continue down to, say, 200 psi, where [the truck] will no longer run, the last cylinder has retained $1000 \mathrm{psi}$ of fuel. Then by throwing a switch, a solenoid opens and now introduces that $1000 \mathrm{psi}$ of fuel back into the other cylinders, and that gives them the equivalent of 2.5 or 3 gallons or so that they can run to the fuel station with. It's not a lot, but the guys are real grateful for it. It's come in handy, you know. This way they don't have to answer to the boss because they forgot to fuel it up. They just throw the switch, run over, get the fuel, and get back to the route."

\section{Leaky fuel supply lines}

"Between the fuel cylinders on the six trucks, when we first got them, they had stainless-steel lines. The stainless-steel line has proved to be too hard and inflexible for mounting between the cylinders, and it wasn't till after about a year or so that we started to develop leaks between the cylinders. We went through and we replaced them all with flex lines. When we first built the trucks, flex lines were not available."

"Also, the use of welded tubing versus seamless tubing, while it does meet the pressure requirements, etc., some of the finish on the welded tubing doesn't work well with the compression fittings. Just minor leaks. And none of the leaks we had were to the extent that they were any where near causing any other problem. What would happen is you'd walk past the vehicle, you'd go, 'Do I smell gas?'"

\section{Emissions}

$\mathrm{T}$ he in-use emissions levels of the truck can be approximated using a chassis dynamometer. The truck is placed on the chassis dynamometer and a driver follows a specific driving cycle while the emissions from the tailpipe are measured. Heavy duty engines are certified for emissions independent of any truck chassis using an engine dynamometer (rather than a chassis dynamometer) and a standardized cycle defined by the Environmental Protection Agency (EPA). Unfortunately, there is currently no accepted standard driving cycle for chassis dynamometer testing of heavy-duty trucks. West Virginia University has tested the New York City trucks on the university's transportable heavy-duty chassis dynamometer using a driving cycle called the Central Business District (CBD) cycle. The CBD cycle is designed to simulate urban stop-andgo driving. 
Because the NYC trucks were placed into service as prototype demonstration and development vehicles, the engines were not optimized for emissions reductions. The emissions results from these prototype trucks have been highly variable. Figure 2 shows the average, minimum, and maximum emissions from the CNG and diesel refuse haulers. Emissions of oxides of nitrogen and carbon monoxide were sometimes less from the CNG trucks and other times less from the diesel trucks. On the average, the diesel trucks emitted less of these types of pollutant.

The total hydrocarbon emissions from the CNG trucks were consistently greater than those from the diesel trucks. However, hydrocarbon emissions from natural gas vehicles are typically $90 \%$ to $95 \%$ methane. EPA and the California Air Resources Board (CARB) regulations are written in terms of nonmethane hydrocarbons because methane does not contribute to urban ozone (smog). The nonmethane hydrocarbon emissions from the CNG trucks were not measured directly, but the values are projected to be similar to, or lower than, those of the diesel trucks.

In particulate emissions, the CNG trucks consistently demonstrated a clear advantage. In 6 of 11 tests performed to date, particulate emissions were essentially zero (too low to measure); the particulate emissions from the diesel trucks averaged about 0.7 grams per mile. This is an attractive feature for a refuse hauler because it operates in populated urban areas where particulate emissions from vehicle exhaust are a serious health concern. The truck drivers have noticed this too. In New York City, the senior drivers get the first choice of trucks and they consistently choose the CNG trucks.

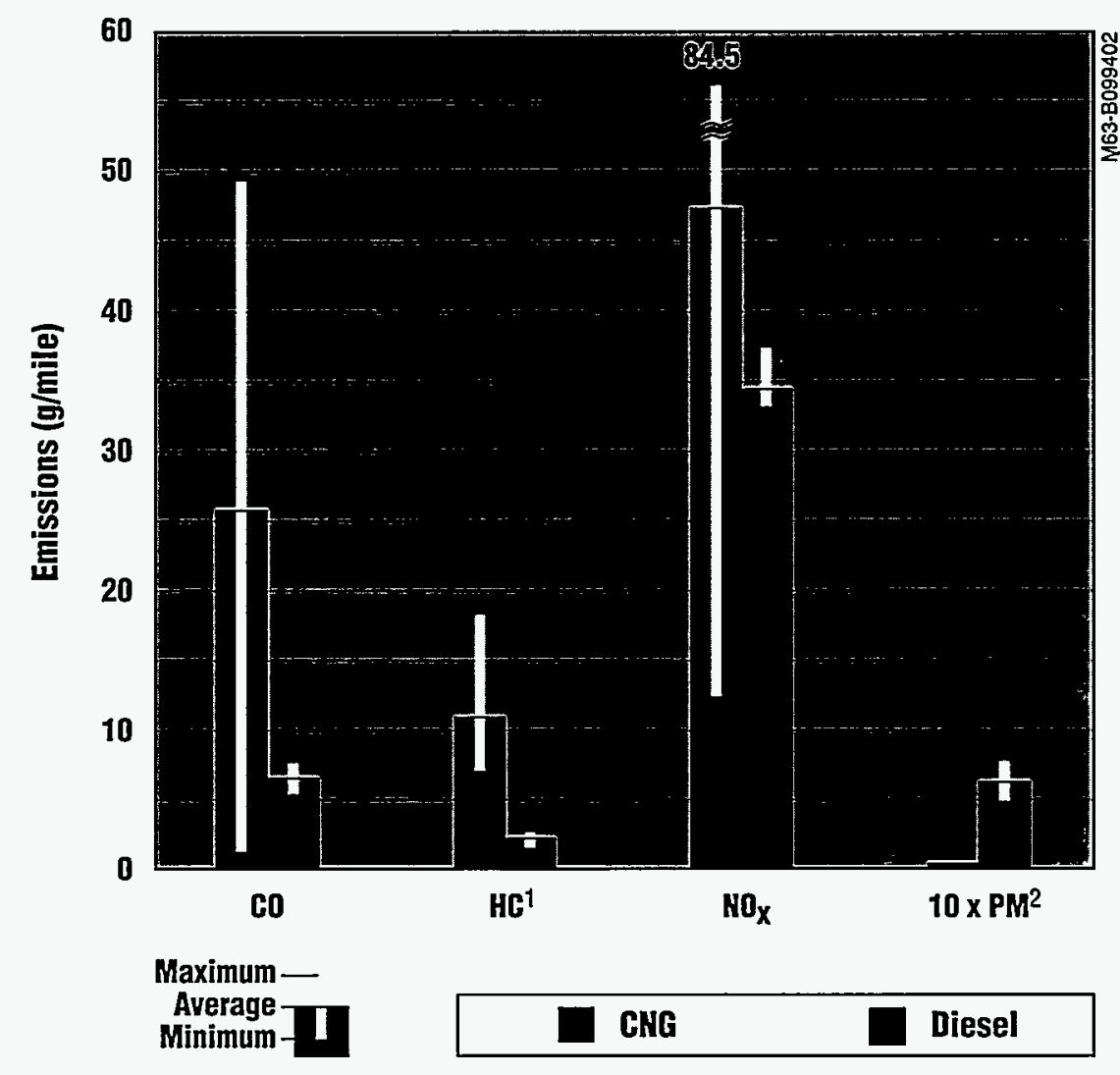

$E P A$ and $C A R B$ require that new engines be emissions-certified using standard procedures on engine (rather than chassis) dynamometer tests. During an engine dynamometer test, the engine is put on a test stand and run through specific loads and speeds while the exhaust emissions are measured. In 1993 and 1994, these tests were performed on emissions-optimized natural gas and diesel versions of the type of engines used in the New York City trucks (Cummins L10). The results of these tests are shown in Figure 3.

It is clear that the natural gas engine emitted significantly less carbon monoxide, oxides of nitrogen, and particulate matter emissions than did the equivalent diesel engine.
Figure 2. Chassis dynamometer emissions results for New York City garbage packers

1 Total hydrocarbons

2 Particulate matter values were magnified 10 times to show results on the same scale 

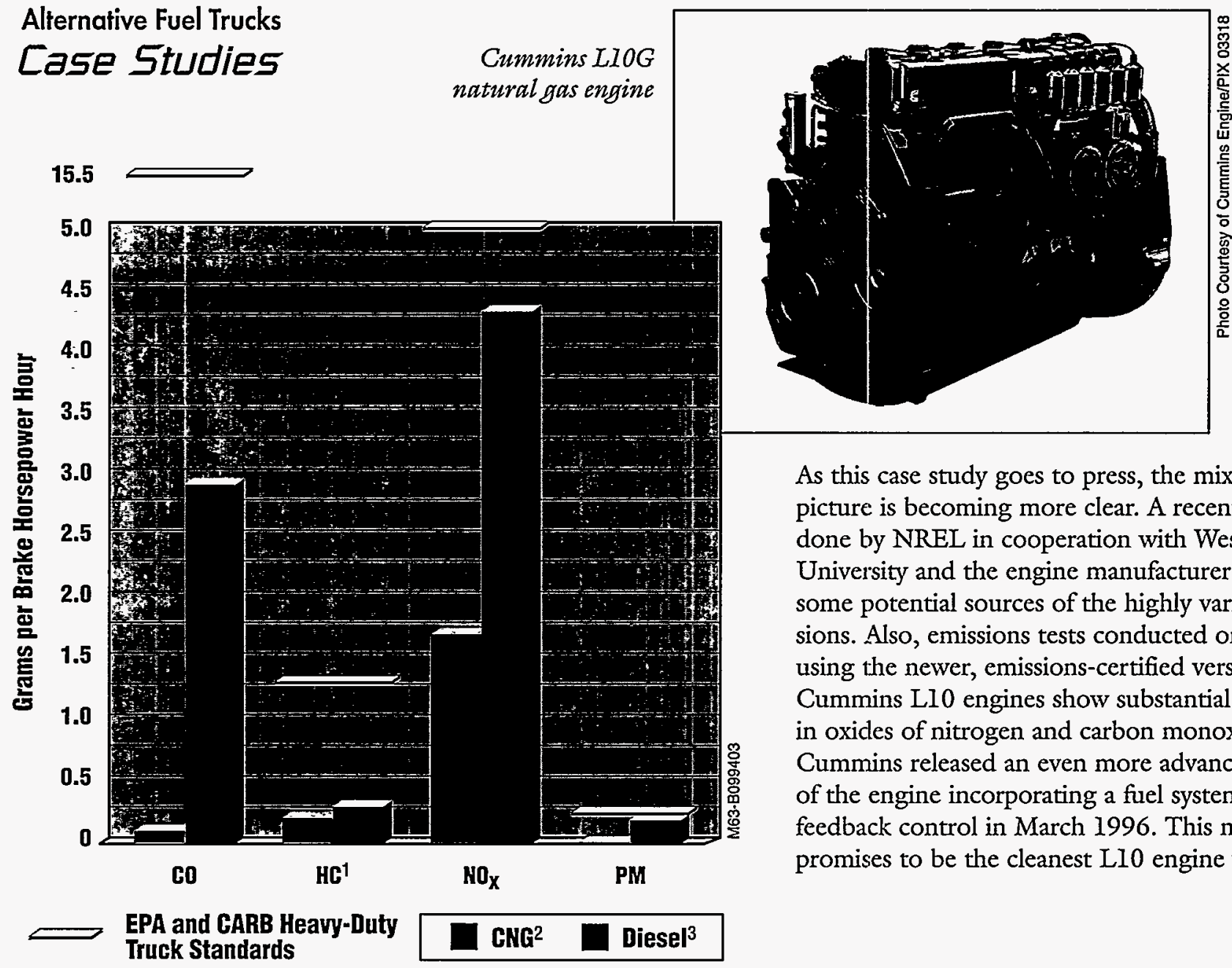

Figure 3. Cummins LIO Diesel and CNG engines emissions certification data from 1993

1 Total hydrocarbons for diesel, nonmethane hydrocarbons for natural gas

2 EPA Certification

3 CARB Certification

\section{More Trudks on the Road ...}

As a result of the excellent performance and driver acceptance of the DOE-sponsored CNG trucks, New York City Department of Sanitation ordered ten additional CNG garbage packers. Five of the new trucks, equipped with Detroit Diesel Corporation Series 50

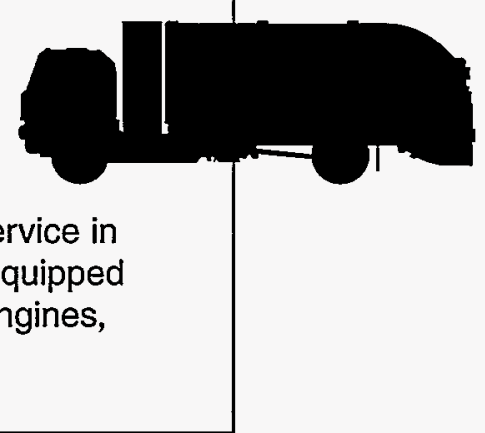

As this case study goes to press, the mixed emissions picture is becoming more clear. A recent study done by NREL in cooperation with West Virginia University and the engine manufacturer has identified some potential sources of the highly variable emissions. Also, emissions tests conducted on transit buses using the newer, emissions-certified versions of the Cummins LI0 engines show substantial reductions in oxides of nitrogen and carbon monoxide emissions. Cummins released an even more advanced version of the engine incorporating a fuel system with full feedback control in March 1996. This new engine promises to be the cleanest LIO engine yet.

For more information visit our World Wide Web site at hitp://www.afdc.doe.gov/0/demoproj/hdv/hdvsect.htmI Call the National Alternative Fuels Hotline at 1-800-423-1DOE, or contact:

Tim Harte

NYC Department of Sanitation (718) 334-9206

Paul Norton

National Renewable Energy Laboratory (303) 275-4424

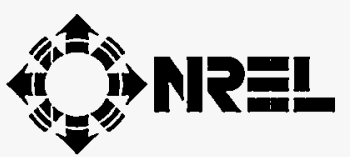

Published by the Center for Transportation Technologies and Systems at the National Renewable Energy Laboratory 1617 Cole Blvd. Golden, CO 80401-3393

DE96000541 NREL/SP-425-20807
February 1995. The other five, equipped with Caterpillar 3306 field test engines, began service in April 1995.
Printed with a renewable-source ink on paper containing at least $50 \%$ wastepaper, including $20 \%$ postconsumer waste 


\section{DISCLAIMER}

This report was prepared as an account of work sponsored by an agency of the United States Government. Neither the United States Government nor any agency thereof, nor any of their employees, makes any warranty, express or implied, or assumes any legal liability or responsibility for the accuracy, completeness, or usefulness of any information, apparatus, product, or process disclosed, or represents that its use would not infringe privately owned rights. Reference herein to any specific commercial product, process, or service by trade name, trademark, manufacturer, or otherwise does not necessarily constitute or imply its endorsement, recommendation, or favoring by the United States Government or any agency thereof. The views and opinions of authors expressed herein do not necessarily state or reflect those of the United States Government or any agency thereof. 